\title{
COPING, STRESS AND BURNOUT IN THE SOUTH AFRICAN POLICE SERVICE IN KWAZULU-NATAL
}

\author{
L. WIESE \\ S. ROTHMANN \\ K. STORM \\ WorkWell: Research Unit for People, Policy and Performance, \\ Faculty of Economic and Management Sciences \\ PU for $\mathrm{CHE}$
}

\begin{abstract}
The objective of this research was to determine the relationship between coping, stress and burnout in the South African Police Service. A survey design was used. The study population $(N=257)$ consisted of police personnel in Kwazulu-Natal. The COPE, Police Stress Inventory and Maslach Burnout Inventory - General Survey (MBI-GS), were used as measuring instruments. Structural equation analysis showed that job demands (as stressors) are associated with exhaustion. Passive coping strategies contributed to exhaustion and cynicism, while seeking emotional support led to lower exhaustion. Exhaustion contributed to cynicism. Stress because of a lack of resources, active coping strategies and not coping passively seem to impact on professional efficacy.
\end{abstract}

\section{OPSOMMING}

Die doelstelling van hierdie navorsing was om die verband tussen coping, stres en uitbranding binne die Suid-Afrikaanse Polisiediens te ondersoek. ' $n$ Opname-ontwerp is gebruik. Die studiepopulasie $(N=257)$ het bestaan uit polisiepersoneel in Kwazulu-Natal. Die COPE, die Polisiestres-Opname en die Maslach-uitbrandingsvraelys - Algemene Opname (MBI-GS) is as meetinstrumente gebruik. Strukturele vergelykingsmodellering het aangetoon dat werkseise (as stressore) geassosieer word met uitputting. Passiewe coping-strategieë het bygedra tot uitputting en sinisme, terwyl die soeke na emosionele ondersteuning tot laer uitputting gelei het. Uitputting het tot sinisme bygedra. Stres a.g.v. 'n tekort aan hulpbronne (invers), aktiewe coping-strategieë en passiewe coping-strategieë (invers) blyk 'n uitwerking op professionele doeltreffendheid te hê.

The productiveness, motivation and health of a police service are regarded as important factors contributing to a country's stability, economic growth and development (Rothmann \& Van Rensburg, 2002). Healthy police officers that are engaged in their work are therefore imperative to furthering these goals. However, police work has been identified as an exceptionally stressful occupation (Alexander, 1999; Anshel, 2000; Paton \& Violanti, 1999). Physical assault, the violent death or suicide of an officer who is a close friend, a response to the death of a child, overt violence, work overload, time pressure and inadequate resources are among the frequently occurring stressors that confront police officers (Carlier \& Gersons, 1992; Kirkcaldy, Cooper \& Ruffalo, 1995).

Regardless the stressful nature of the police profession, only a few studies focused on burnout among police officers. Within the human service occupations, burnout is predominantly researched in the health $(33,8 \%)$ and teaching $(26,6 \%)$ professions. Law enforcement constitutes only 3,4\% of all burnout research on occupations (Schaufeli \& Enzmann, 1998). Therefore, it seems necessary to investigate the burnout and possible causes thereof in the South African Police Service (SAPS).

Burnout can be defined as "a persistent, negative, work-related state of mind in 'normal' individuals that is primarily characterised by exhaustion, accompanied by distress, a sense of reduced effectiveness, decreased motivation, and the development of dysfunctional attitudes and behaviours at work" (Schaufeli \& Enzmann, 1998, p. 36). Research over the past two decades has shown that burnout is not only related to negative outcomes for the individual, including depression, a sense of failure, fatigue, and loss of motivation, but also to negative outcomes for the organisation, including absenteeism, high turnover rates and lowered productivity (Schaufeli \& Enzmann, 1998). This is also true for the police profession.

Schaufeli and Enzmann (1998) classified possible factors contributing to burnout into four categories namely

Requests for copies should be addressed to: S Rothmann, WorkWell: Research Unit for People, Policy and Performance, Faculty of Economic \& Management Sciences, PU for CHE, Private Bag X6001, Potchefstroom, 2520 biographical characteristics, personality characteristics, work related attitudes and work and organisational characteristics (Schaufeli \& Enzmann, 1998). For the purpose of this research, the focus will be organisational stress.

Organisational factors which contribute to burnout are lack of social support, rotating shifts, work overload, role conflict, and role ambiguity and lack of feedback (Alexander, 1999; Biggam, Power, MacDonald, Carcary \& Moodie, 1997; McCafferty, McCafferty \& McCafferty, 1992). These factors represent "demands" on employees (also referred to as job stressors), that are included in most models of burnout (Schaufeli \& Enzmann, 1998). It has also been found that burnout is related to organisational stressors including low levels of perceived control and a lack of resources.

One of the basic issues in the burnout domain concerns coping, or ways in which an individual can attempt to deal with organisational stressors to ward off aversive strains (Beehr, Johnson \& Nieva, 1995). Lazarus and Folkman (1984, p. 141) define coping as "constantly changing cognitive and behavioural efforts to manage specific external and/or internal demands that are appraised as taxing or exceeding the resources of the person". When a successful coping strategy is followed (e.g. problem-solving), goals are achieved, professional efficacy is enhanced and a sense of existential significance is fostered. By contrast, when a poor coping strategy is adopted (e.g. passive coping), burnout is likely to develop (Schaufeli \& Enzmann, 1998). Therefore, high levels of burnout are associated with ineffective (Rowe, 1997) or withdrawal coping strategies and low degrees of burnout with constructive coping strategies (Maslach \& Jackson, 1982; Maslach, Schaufeli \& Leiter, 2001). Furthermore, burnout is also seen as a self-perpetuating process not only because it impedes the attainment of professional goals, but also because it depletes coping resources (Schaufeli \& Enzmann, 1998).

Based on the above discussion, it is clear that burnout poses a serious threat to officers in the SAPS and that coping strategies and organisational stressors might be related to burnout of police members. However, no studies regarding the role of 
coping strategies and organisational stressors in burnout of police members in South Africa, and more specifically in Kwazulu-Natal, were found in the literature. The objective of this research was to determine the relationship between coping, organisational stress and burnout of police officers in Kwazulu-Natal. If significant relationships between these variables are found, programmes could be implemented to prevent or manage burnout.

\section{Burnout in the police profession}

The term 'burnout' was traditionally only used with reference to people working in the human services (Maslach et al., 2001; Van Dierendonck, Schaufeli \& Buunk, 1998). However, the burnout concept has recently been expanded towards all other professions and occupational groups (Maslach et al., 2001). This makes it possible to determine the burnout level of people in various occupations, including the police profession. The need for an instrument that measures burnout in occupations other than the human services was met by the introduction of the Maslach Burnout Inventory - General Survey (MBI-GS: Schaufeli, Leiter, Maslach \& Jackson, 1996). The MBI-GS assesses parallel dimensions to those contained in the original MBI, except the items that do not explicitly refer to working with people. The MBI-GS comprises the following dimensions:

- Exhaustion refers to feelings of being overextended and depleted of one's emotional and physical resources.

- Cynicism refers to a negative, callous or detached response to various aspects of the job.

- Low professional efficacy refers to the self-evaluation dimension of burnout and is a feeling of competence, productivity and achievement at work.

Law enforcement has been identified as a particular stressful occupation world-wide (Anshel, 2000; Burke, 1994; Goodman, 1990; Gulle, Tredoux \& Foster, 1998). An alarming rise in suicide statistics, medical boardings (particularly for psychological reasons), divorce statistics, and alcohol and drug abuse (Gulle et al., 1998; Nel \& Burgers, 1998; Venter, 1993) was found among members of the SAPS. Gulle et al. (1998) showed that the SAPS experienced a greater degree of stress than a police sample from the United States of America. Given these high levels of stress, it seems as if police officers in the SAPS are prone to experience high levels of burnout, specifically in the Kwazulu-Natal Province. Most crimes were committed in Gauteng and KwaZulu-Natal. Murders as a result of political/faction fighting mainly occur in KwaZulu-Natal and Gauteng (93\%), while most $(80 \%)$ witchcraft-related murders happen in KwaZulu-Natal (Crime Intelligence, 2001).

Although it is not possible to accurately estimate the prevalence of burnout, a relative comparison between levels of burnout across various occupational fields and professions has revealed high levels of cynicism and reduced professional efficacy in law enforcement (Schaufeli \& Enzmann, 1998). The study holds that this profile is consistent across nations. In contrast to these findings, a South African study by Pieters (1995) indicated low levels of burnout among SAPS personnel. It must be mentioned that he used an unstandardised measuring instrument.

\section{Burnout, organisational stress and coping}

With reference to the work- setting, there exists considerable evidence exists that particularly work stressors influence burnout (Burke, 1994). Schaufeli and Enzmann (1998) state that burnout and stress are two distinct concepts. Stress could be seen as a temporary adaptation process that is accompanied by mental and physical symptoms (Brill, 1984). On the other hand, Schaufeli and Enzmann (1998) consider burnout as a particular kind of prolonged job stress. Therefore, an individual who experiences stress must be able to return to his/her normal level of functioning (adaptation has been successfully performed), while burnout refers to a breakdown in adaptation, accompanied by chronic malfunctioning at work.
Two major categories of stressors are often mentioned by police officers. Inherent police stressors refer to the various aspects of the very nature of police work, such as danger, violence and crime (Alexander, 1999; Kop, Euwema \& Schaufeli, 1999). Organisational stressors refer to stress as a result of certain characteristics of the police organisation itself and include stressors such as management style, staff shortages, inadequate resources, lack of communication and work overload (Kop et al., 1999). Researchers view inherent stressors as apartseparate from organisational stressors (Biggam et al., 1997; Brown \& Campbell, 1990, 1994; Violanti \& Aron, 1994). Findings also indicate that the latter are more prevalent compared to the former (Brown \& Campbell, 1990, 1994; Kop et al., 1999; Violanti \& Aron, 1994).

According to Schaufeli and Enzmann (1998), organisational stressors can be divided into two groups, namely job demands and a lack of job resources. Leiter and Maslach (1988) also considered job demands and resources as potential sources of organisational stress as in the stress-strain-coping-selfevaluation process of Lazarus and Folkman (1984). In order to understand how job demands and resources are related to burnout, the conservation of resources (COR) theory of stress (Hobfoll, 1989; Hofboll \& Freedy, 1993) will be used as framework. COR theory suggests that people strive to obtain and maintain that which they value (their resources). Thus, burnout occurs when certain valued resources are lost, are inadequate to meet demands, or do not yield the anticipated level of return. Major job demands include role ambiguity, role conflict, stressful events, heavy workload and work pressure. Major resources include social support from various sources; job enhancement opportunities, such as control, participation in decision making and autonomy; and reinforcement contingencies (Burke \& Richardsen, 1993; Cordes \& Dougherty, 1993).

Various studies confirm the relationship between burnout, job demands and resources. In a proposed process model of burnout, Leiter $(1991,1993)$ found that job demands are more strongly related to exhaustion, while job resources are more strongly related to cynicism and professional efficacy. Lee and Ashforth's (1996) results revealed that job demands were strongly associated with exhaustion, cynicism was associated with both resources and demands and professional efficacy was largely uncorrelated to job demands and job resources. Schaufeli and Enzmann (1998) analysed 27 published studies and found that job demands correlate most strongly with exhaustion and least with professional efficacy. They also found that professional efficacy shows a comparatively strong association with resources. Using the MBI-GS, Taris, Schreurs and Schaufeli (1999) found that job demands were more strongly related to exhaustion, while cynicism and professional efficacy were related to the resource variables, while Peeters and Le Blanc (2001) found that organisational demands relate only to exhaustion. Based on these results, it could be expected that job demands will be most strongly associated with exhaustion, where a lack of job resources will be strongly associated with lower professional efficacy.

Some researchers have suggested that individual coping strategies may be important in ameliorating or exacerbating psychological burnout (Alsoofi, Al-Heeti \& Alwashli, 2000; Anshel, 2000; Golembiewski \& Munzenrider, 1988). Coping refers to the cognitive and behavioural strategies that individuals use to manage a stressful situation, as well as the negative emotional reactions elicited by that event (Folkman, Lazarus, Gruen \& DeLongis, 1986). Violanti (1992) found that the coping strategies of distancing and planful problem solving significantly reduced distress, while escape/avoidance and selfcontrol coping did not work in the police situation. Other maladaptive coping strategies found among police officers include alcohol and drug use, anger and withdrawal (Burke, 1993; Violanti, Marshall \& Howe, 1985). Also, more coping 
strategies (Violanti, 1992) and poor coping skills are positively related to the intensity and frequency with which stress is experience in police work (Anshel, 2000).

Research on burnout suggest that certain coping strategies have been found to be effective in reducing burnout, while other strategies have increased levels of burnout as result. Pines and her colleagues (Pines, Aronson \& Kafry, 1981) found that active coping efforts, such as confronting the problem, were associated with lower levels of burnout, and inactive efforts such as avoidance and drinking were associated with higher levels of burnout. Rohman (1987/1988) did not support the finding that active coping moderated the relation between the stressor and burnout. Anderson (2000) found that when individuals used active coping strategies, feelings of cynicism lessened and their sense of professional efficacy increased. However, it did not save them from exhaustion. In a sample of pharmacists, Storm and Rothmann (2003) found that personal accomplishment (professional efficacy) was the only component of burnout associated with coping strategies. Active coping strategies were associated with higher levels of personal accomplishment. In conclusion, it seems as if active coping will be associated with lower levels of cynicism, and higher levels of professional efficacy.

Passive or avoidance coping seems to be associated with increased levels of burnout. Mitchell and Hastings (2001) found that the use of disengagement coping strategies predicted both exhaustion and less positive feelings of professional efficacy. Anderson (2000) found that workers who used avoidance coping strategies more, showed an increase in exhaustion. Chan and Hui (1995) observed that the use of passive or avoidance coping was associated with all three dimensions of burnout. According to Schaufeli and Enzmann (1998), avoidance coping strategies share about $5-10 \%$ of the variance of exhaustion and cynicism, where the relationship with personal accomplishment is weaker (less than 5\%). Rohman $(1987 / 1988)$ also found a positive relationship between avoidance coping and exhaustion and cynicism. Therefore it seems as if passive coping strategies are associated with increased levels of exhaustion and cynicism.

Teague (1992) interviewed 163 nurses in one hospital and concluded that those who utilised more emotion-oriented coping styles reported the highest amount of burnout. Although emotion-focused coping strategies are often considered as ineffective (Chwalisz, Altmaier \& Russel, 1992; Patterson, 1999), Zellars and Perrewé (2001) argue that emotion-focused strategies are multidimensional and have suffered from a negative reputation primarily as a result of their measurement. Their results provide empirical support for the valuable effect of emotional social support as an aid against all three dimensions. Others also suggested that emotional support could alleviate work stress and psychological strain (Carver, Scheier \& Wieintraub, 1989; Cherniss, 1980). On the other hand, there is evidence that emotional social support may not always be very adaptive (Billings \& Moos, 1984; Costanza, Derlega \& Winstead, 1988). Furthermore, Hobfoll, Freedy, Lane and Geller (1990) suggested that although social resources may help counterbalance environmental demands, people may be reluctant to call on support out of fear of being a burden. It can therefore be concluded that emotional support could buffer the effect of burnout, if the emotional support resources available are utilised.

\section{RESEARCH METHOD}

\section{Research design}

A survey design was used to reach the research objective. The specific design is the cross-sectional design, whereby a sample is drawn from a population at one time (Shaughnessy \& Zechmeister, 1997).

\section{Sample}

Random samples $(n=257)$ were taken from small, medium and large police stations in Kwazulu-Natal. Stations were divided into small (less than 25 staff members), medium (25 100 staff members) and large (more than 100 staff members) stations. All police members at randomly identified small and medium stations in each of the provinces were asked to complete the questionnaires. In the large stations stratified random samples were taken according to gender and race. Table 1 provides a summary of the characteristics of the sample used in this study.

TABLE 1

ChaRacteritics OF THE SAMPLE $(\boldsymbol{N}=\mathbf{2 5 7})$

\begin{tabular}{|c|c|c|}
\hline Characteristic & Category & ercentage of Respondents \\
\hline \multirow[t]{4}{*}{ Race } & White & 11,98 \\
\hline & Black & 52,89 \\
\hline & Coloured & 2,48 \\
\hline & Indian & 32,64 \\
\hline \multirow[t]{6}{*}{ Rank } & Constable & 10,87 \\
\hline & Sergeant & 10,87 \\
\hline & Inspector & 50,87 \\
\hline & Captain & 16,09 \\
\hline & Superintendent & 2,17 \\
\hline & Senior Superintendent & 9,13 \\
\hline \multirow[t]{7}{*}{ Education } & Grade 10 & 8,37 \\
\hline & Grade 11 & 3,59 \\
\hline & Grade 12 & 53,39 \\
\hline & Technical College Diploma & 3,19 \\
\hline & Technikon Diploma & 27,49 \\
\hline & University Degree & 2,39 \\
\hline & Postgraduate Degree & 1,59 \\
\hline \multirow[t]{2}{*}{ Gender } & Male & 78,31 \\
\hline & Female & 21,69 \\
\hline \multirow[t]{5}{*}{ Marital Status } & Single & 29,48 \\
\hline & Married & 39,84 \\
\hline & Divorced & 27,49 \\
\hline & Separated & 1,59 \\
\hline & Remarried & 1,59 \\
\hline \multirow[t]{8}{*}{ Language } & Afrikaans & 10,24 \\
\hline & English & 35,83 \\
\hline & Sepedi & 0,39 \\
\hline & Sesotho & 0,79 \\
\hline & IsiSwati & 0,79 \\
\hline & IsiNdebele & 0,39 \\
\hline & IsiXhosa & 0,39 \\
\hline & IsiZulu & 51,18 \\
\hline \multirow[t]{2}{*}{ Medical Condition } & Yes & $14,80]$ \\
\hline & No & 85,20 \\
\hline
\end{tabular}

According to Table 1 , the majority of participants were Black $(52,89 \%)$, Inspectors $(50,87 \%)$ and had an educational level of Grade 12 (53,39\%). Male participants constituted 78,31\% of participants and the majority of participants were married (39,84\%). $51,18 \%$ of respondents were Zulu-speaking, 35,83\% were English-speaking and 10,24\% were Afrikaans-speaking. The majority of respondents were without a medical condition that couldan influence work performance $(85,20 \%)$. $83,20 \%$ of respondents had been charged for previous offences, while $14,80 \%$ had medical conditions affecting their quality of work. 


\section{Measuring instruments}

The COPE Questionnaire (COPE) wasis used to measure participants' coping strategies. The COPE is a multidimensional 53-item coping questionnaire that indicates the different ways that people cope in different circumstances (Carver et al., 1989). Although the original questionnaire measures 13 different coping strategies, Pienaar and Rothmann (in 2002press) subjected the COPE to a principal components factor analysis with a varimax rotation. Three internally consistent factors were extracted, namely Active Coping (16 items), Passive Coping (13 items), and Seeking Emotional Support ( 7 items). The alpha coefficients of the three scales are $0,93,0,86$, and 0,87 respectively. All these values are acceptable $(\alpha>0,70$, Nunnally \& Bernstein, 1994), and thus indicate the internal consistency of the factors of the PSI. Test-retest reliability varies from 0,46 to 0,86 and from 0,42 tot 0,89 (applied after two weeks).

The Police Stress Inventory (PSI) wasis used to measure participants' organisational stress. The PSI focuses on common work situations that often result in psychological strain. Each of the 44 items describes a job-related stressor event and assesses both the perceived severity and frequency occurrence of that event. Firstly, participants rated each of the 44 items regarding the intensity of stress on a 9-point scale. The frequency part of the questionnaire asked "how many times in the last six months" did youthe participant experience the source of stress. Pienaar and Rothmann (in 2002press) subjected the PSI to a principal components factor analysis with a vearimax rotation. Three internally consistent factors were extracted, namely Job demandsJob Demands (17 items), Lack of resources (14 items), and Police-specific Demands (8 items). The alpha coefficients of the three scales are 0,$92 ; 0,92$; and 0,89 respectively. All these values are acceptable $(\alpha>0,70$, Nunnally \& Bernstein, 1994), and thus indicate the internal consistency of the factors of the PSI.

The Maslach Burnout Inventory-General Survey (MBI-GS) (Schaufeli et al., 1996) wasis used to measure burnout. The MBI-GS has three subscales: Exhaustion (Ex) (five items; e.g. "I feel used up at the end of the workday"), Cynicism (Cy) (five items; e.g. "I have become less enthusiastic about my work") and Professional Efficacy (PE) (six items; e.g. "In my opinion, I am good at my job"). Together the subscales of the MBI-GS provide a three-dimensional perspective on burnout. Internal consistencies (Cronbach alpha coefficients alphas) reported by Schaufeli et al. (1996) varied from 0,87 to 0,89 for Exhaustion, 0,73 to 0,84 for Cynicism and 0,76 to 0,84 for Professional Efficacy. Test-retest reliabilities after one year were 0,65 (Exhaustion), 0,60 (Cynicism) and 0,67 (Professional Efficacy) (Schaufeli et al., 1996). All items are scored on a 7 -point frequency rating scale ranging from 0 ("never") to 6 ("daily"). Storm and Rothmann (2002in press) confirmed the 3 -factor structure of the MBI-GS in a sample of 2396 SAPS members, but recommended that Item 13 should be dropped from the questionnaire. She confirmed the structural equivalence of the MBI-GS for different race groups in the SAPS. The following Cronbach alpha coefficients were obtained for the MBI-GS: Exhaustion: 0,88; Cynicism: 0,79; Professional Efficacy: 0,78 (Storm, 2002 \& Rothmann, in press).

\section{Statistical analysis}

The statistical analysis was carried out with the help of the SASprogram (SAS Institute, 2000) and the AMOS programme (Arbuckle, 1997). Cronbach alpha coefficients, inter-item correlation coefficients and confirmatory factor analysis were used to assess the reliability and validity of the measuring instruments (Clark \& Watson, 1995). Descriptive statistics (e.g. means, standard deviations, skewness and kurtosis) were used to analyse the data.
Pearson product-moment correlations were used to specify the relationships between the variables. In the case where the distribution of scores was skew, Spearman correlations were computed. A cut-off point of 0,30 (medium effect, Cohen, 1988) was set for the practical significance of correlation coefficients.

Canonical correlation was used to determine the relationships between the dimensions of coping, stress and burnout. The goal of canonical correlation is to analyse the relationship between two sets of variables (Tabachnick \& Fidell, 2001). Canonical correlation is considered a descriptive technique rather than a hypothesis-testing procedure.

Structural equation modeling (SEM) methods as implemented by AMOS (Arbuckle, 1997) were used to construct a causal model of burnout. The following goodness-of-fit indices were used to summarise the degree of correspondence between the implied and observed covariance matrices: (1) The $\chi^{2}$ goodness-of-fit statistic. A large $\chi^{2}$ relative to the degrees of freedom, indicates a need to modify the model to better fit the data; (2) The $\chi^{2}$ /degrees of freedom ratio (CMIN/DF) (Wheaton, Muthén, Alwin \& Summers, 1977). (3) The Goodness of Fit Index (GFI) indicates the relative amount of the variances/co-variances in the sample predicted by the estimates of the population. It usually varies between 0 and 1 and a result of 0,90 or above indicates a good model fit; (4) The Adjusted Goodness-of-Fit Index (AGFI) is a measure of the relative amount of variance accounted for by the model, corrected for the degrees of freedom in the model relative to the number of variables; (5) The parsimony goodness-of-fit index (PGFI) takes into account the complexity of the hypothesised model in the assessment of overall model fit and provides a more realistic evaluation of the hypothesised model. Byrne (2001) suggested values $>0,80$ are considered to be appropriate; (6) The Normed Fit Index (NFI) represents the point at which the model being evaluated falls on a scale running from a null model to perfect fit. This index is normed to fall on a 0 to 1 continuum; (7) The Comparative Fit Index (CFI) represents the class of incremental fit indices in that it is derived from the comparison of a restricted model with that of an independence (or null) model in the determination of goodness-of-fit; (8) The Tucker-Lewis Index (TLI; Tucker \& Lewis, 1973) is a relative measure of covariation explained by the model that is specifically developed to assess factor models. For NFI, CFI and TLI, it is more or less generally accepted that a value less than 0,90 indicates that the fit of the model can be improved (Hoyle, 1995), although a revised cutoff value close to 0,95 has recently been advised ( $\mathrm{Hu} \&$ Bentler, 1999); (9) The Root Mean Square Error of Approximation (RMSEA) estimates the overall amount of error; it is a function of the fitting function value relative to the degrees of freedom. Hu and Bentler (1999) suggested a value of 0,06 to be indicative of good fit between the hypothesised model and the observed data.

\section{RESULTS}

Table 2 shows the descriptive statistics, Cronbach alpha coefficients and inter-item correlation coefficients of the measuring instruments.

Table 2 shows that acceptable Cronbach alpha coefficients varying from 0,69 to 0,92 were obtained for the scales (see Nunnally \& Bernstein, 1994). The mean inter-item correlations of most of the scales are acceptable $(0,15<r<0,50$, Clarke \& Watson, 1995). The inter-item correlations of two scales, namely Exhaustion, and Police-specific Demands, are somewhat high. 
TABLE 2

DESCRIPTIVE STATISTICS, CRONBACH ALPHA COEFFICIENTS AND INTER-ITEM CORRELATION COEFFICIENTS OF THE MEASURING INSTRUMENTS $(N=257)$

\begin{tabular}{lrrrrrr}
\hline Item & Mean & SD & \multicolumn{5}{l}{ Skewness } & Kurtosis Inter-item r & $\alpha$ \\
\hline MBI-GS & & & & & & \\
Exhaustion & 12,58 & 8,33 & 0,45 & $-0,63$ & 0,56 & 0,86 \\
Cynicism & 8,14 & 6,41 & 0,58 & $-0,51$ & 0,46 & 0,77 \\
Professional Efficacy & 28,21 & 7,07 & $-1,21 *$ & $1,45 *$ & 0,34 & 0,74 \\
PSI & & & & & & \\
Job Demands & 85,73 & 29,62 & $-0,20$ & $-0,44$ & 0,41 & 0,92 \\
Job Resources & 81,83 & 25,56 & $-0,43$ & $-0,34$ & 0,46 & 0,92 \\
Police-specific Demands & 41,63 & 18,82 & $-0,14$ & $-1,09$ & 0,57 & 0,91 \\
COPE & & & & & & \\
Problem-focused Coping & 66,76 & 11,84 & $-0,37$ & $-0,41$ & 0,29 & 0,90 \\
Passive Coping & 28,31 & 8,38 & 0,48 & $-0,23$ & 0,31 & 0,85 \\
Seeking Social Support & 20,30 & 5,21 & $-0,58$ & $-0,27$ & 0,46 & 0,85 \\
Turning to Religion & 12,32 & 3,03 & $-0,72$ & $-0,02$ & 0,42 & 0,74 \\
\hline
\end{tabular}

* High skewness and kurtosis

It is evident from Table 2 that most of the scales of the measuring instruments have relatively normal distributions, with low skewness and kurtosis. It is only Professional Efficacy that shows relatively high skewness and kurtosis, but it is still acceptable.

Table 3 reports the product-moment correlation coefficients between burnout, coping and stress. In the case of the correlation between Professional Efficacy and the other constructs, Spearman correlation coefficients were computed because of the skewed distribution of Professional Efficacy. Table 3 shows the Spearman correlation coefficients between Professional Efficacy and the other constructs.

TABLE 3

Product-moment Correlation Coefficients BETWEEN BURNOUT, STRESS AND COPING

\begin{tabular}{lccc}
\hline Item & Exhaustion & Cynicism & Professional Efficacy \\
\hline Problem-focused Coping & $-0,03$ & $-0,03$ & $0,22 *$ \\
Passive Coping & $0,322^{*+}$ & $0,41^{*+}$ & $-0,25 *$ \\
Seeking Social Support & $-0,04$ & 0,02 & 0,28 \\
Turning to Religion & $-0,00$ & $-0,04$ & 0,09 \\
Job Demands & $0,53{ }^{*++}$ & $0,35{ }^{*+}$ & 0,07 \\
Job Resources & $0,47^{*+}$ & $0,28 *$ & $0,21 *$ \\
Police-specific Demands & $0,37 *$ & $0,17 *$ & $0,17 *$ \\
\hline
\end{tabular}

${ }^{*} \mathrm{p} \leq 0,05$, statistically significant

$+r>0,30$, practically significant, medium effect

$++r>0,50$, practically significant, large effect

Exhaustion correlates practically significantly positively with Job Demands, Job Resources and Passive Coping. Cynicism is practically significantly positively correlated with Job Demands and Passive Coping.

The analysis of the intensity and frequency of the extracted factors on the PSI, namely Job Demands, Lack of Resources and Police-specific Demands, is given in Table 4.

Table 4 shows that Lack of Resources can be identified as the stressor with the highest intensity and frequency. Staff shortages, inadequate salaries and other officers not doing their job can be seen as stressors with a high intensity and average frequency. Other stressors, like a lack of officers to handle specific tasks, inadequate or poor quality equipment, a lack of recognition for work well done, negative attitudes towards the organisation, and poorly motivated co-workers, can be seen as stressors with an average intensity and that occur relatively frequently. Inadequate supervision is a stressor with an average intensity, but it does not occur on a regular basis. Regarding stressors associated with Job Demands, having to deal with crisis situations, excessive paper-work, having to perform tasks not in job description and having to do someone else's work, were found to be the stressors with the highest intensity and frequency. Seeing criminals go free is one of the police-specific demands with the highest intensity and frequency. A fellow officer killed in the line of duty is also very stressful, but this stressor is very low in frequency.

TABLE 4

THE INTENSITY AND FREQUENCY OF JOB DEMANDS, LACK OF RESOURCES AND POLICE-SPECIFIC DEMANDS

\begin{tabular}{lccc}
\hline Factor and Items & Intensity & Frequency & Severity \\
\hline Job Demands & & & \\
11 Being assigned more responsibility & 5,21 & 4,59 & 23,91 \\
7 Having to deal with crisis situations & 5,14 & 4,19 & 21,54 \\
31 Having to work shift-work & 4,21 & 3,50 & 14,74 \\
28 Having to do someone else's work & 5,72 & 5,47 & 31,29 \\
2 Having to work overtime & 4,66 & 3,76 & 17,52 \\
23 Being frequently interrupted & 5,32 & 4,71 & 25,06 \\
25 More paper-work you can handle & 5,96 & 5,51 & 32,84 \\
9 Having to perform tasks that are & 5,78 & 5,29 & 30,58 \\
not part of your job description & & & \\
Job Resources & & & \\
15 Lack of officers to handle specific tasks & 5,91 & 5,13 & 30,32 \\
10 Inadequate or poor quality equipment & 6,30 & 5,47 & 34,46 \\
8 Lack of recognition for work well done & 6,03 & 4,57 & 27,56 \\
5 Other officers not doing their job & 6,22 & 5,49 & 34,15 \\
14 Negative attitudes experienced & 5,18 & 3,88 & 20,10 \\
towards the organisation & & & \\
29 Other officers poorly motivated & 5,96 & 5,40 & 32,18 \\
19 Inadequate salary & 6,57 & 5,74 & 37,71 \\
21 Supervision is poor or inadequate & 5,37 & 3,84 & 20,62 \\
36 Staff shortages & 6,88 & 6,18 & 42,52 \\
Police-specific Demands & & & \\
44 Seeing criminals go free & 6,57 & 4,59 & 30,16 \\
43 Having to deal with the media & 4,04 & 2,08 & 8,40 \\
38 Fellow officer killed in the line of duty & 5,83 & 2,13 & 12,42 \\
37 Killing someone in the line of duty & 5,13 & 1,75 & 8,98 \\
39 Racial conflict & 5,40 & 3,13 & 16,90 \\
\hline & & & \\
\hline
\end{tabular}

Table 5 reports the results of the canonical analysis of stress, coping and burnout.

The first canonical correlation was $0,63(39,47 \%$ overlapping variance); the second was 0,48 (23,07\% overlapping variance). The other canonical correlation was 0,14 . With all three canonical correlations included, $F(21,706,93)=10,55$ and $F(12,494)=6,21$ and $p<0,0001$. Subsequent F-tests were not statistically significant. Therefore, the first two pairs of canonical variates accounted for the significant relationships between the two sets of variables. Total percentage of variance and total redundancy indicate that the first set of canonical variates was only somewhat related, while the second set was moderately related.

With a cut-off correlation of 0,30 , the variables in the first variable set that correlated with the first canonical variate, were Job Demands, Lack of Resources, Police-specific 
Demands and Passive Coping. Among the second variable set, Exhaustion and Cynicism were correlated with the first canonical variate. For the first canonical variate it is indicated that job demands $(0,77)$, lack of job resources $(0,59)$, policespecific demands $(0,42)$ and passive coping strategies $(0,73)$ are associated with high levels of exhaustion $(0,88)$ and cynicism $(0,79)$.

TABLE 5

RESULTS OF THE CANONICAL ANALYSIS: STRESS, COPING AND BURNOUT

\begin{tabular}{lcc}
\hline Variable & $\begin{array}{c}\text { First Canonical } \\
\text { Variate }\end{array}$ & $\begin{array}{c}\text { Second Canonical } \\
\text { Variate }\end{array}$ \\
\hline
\end{tabular}

Correlation Coefficient Correlation Coefficient

\section{VARIABLE SET 1}

$\begin{array}{lrrrr}\text { Job Demands } & 0,77 & 0,45 & 0,50 & 0,13 \\ \text { Job Resources } & 0,59 & 0,17 & 0,68 & 0,44 \\ \text { Police-specific Demands } & 0,42 & 0,01 & 0,65 & 0,29 \\ \text { Active Coping } & -0,16 & -0,29 & 0,36 & 0,64 \\ \text { Passive Coping } & 0,73 & 0,68 & -0,34 & -0,53 \\ \text { Seeking Emotional Support } & -0,04 & -0,04 & -0,05 & -0,40 \\ \text { Turning to Religion } & -0,06 & -0,10 & 0,14 & 0,20 \\ \text { Percent of Variance } & 0,24 & & 0,20 & \text { Total }=0,44 \\ \text { Redundancy } & 0,10 & & 0,05 & \text { Total }=0,15 \\ & & & & 0,53 \\ \text { VARIABLE SET 2 } & 0,88 & 0,69 & 0,44 & -0,35 \\ \text { Exhaustion } & 0,79 & 0,42 & -0,08 & 0,83 \\ \text { Cynicism } & -0,22 & -0,30 & 0,89 & \text { Total }=0,81 \\ \text { Professional Efficacy } & 0,48 & & 0,33 & \text { Total }=0,27 \\ \text { Percent of Variance } & 0,19 & & 0,08 & \\ \text { Redundancy } & 0,63 & & 0,48 & \\ \text { Canonical Correlation } & & & & \end{array}$

The variables in the first variable set that correlated with the second canonical variate, were Job Demands, Lack of Resources, Police-specific Demands, Active Coping and Passive Coping. Among the second variable set, Exhaustion and Professional Efficacy were correlated with the second canonical variable. For the second canonical variate it is indicated that job demands $(0,50)$, lack of job resources $(0,68)$, police-specific demands $(0,65)$, active coping $(0,36)$ and a low score on passive coping $(-0,34)$ are associated with exhaustion $(0,44)$ and professional efficacy $(0,90)$.

Structural equation modelling as implemented by AMOS (Arbuckle, 1997) was used to test more comprehensive hypothesised relationships. Based on the results of the canonical correlations, lacking associations between organisational stress, coping and burnout were not included in the SEM analysis. A model was constructed based upon the results of the canonical correlations and the consensus of findings from a review of the burnout literature. The manner by which each of the constructs in the model is to be measured was established by the combination of particular items for each variable in the model. To ensure that each variable is psychometrically sound, alpha coefficients were computed for the items representing each construct. The fit of the hypothetical model was assessed by a quick overview of the overall ( $\chi^{2}$ value (together with its degrees of freedom and probability value) and global assessments of model fit based on several goodness-of-fit statistics (GFI, AGFI, PGFI, NFI, TLI, CFI and RMSEA). Given findings of an ill-fitting initially hypothesised model, possible misspecifications as suggested by the so-called modification indexes were looked for and eventually a revised, re-specified model was fitted to the data.

The hypothesised model

The formulation of the hypothesised model is shown in Figure 1. As can be seen, burnout is represented as a multidimensional construct with Exhaustion, Cynicism and Professional Efficacy operating as conceptually distinct factors.

The manner by which each of the constructs in this model is to be measured is by multiple indicators of each construct through the judicious combinations of particular items. As such, items were carefully grouped according to content and factor loadings in order to equalise the measurement weighting across indicators. Alpha coefficients for the particular items representing each construct were as follows: Exhaustion $(0,81)$, Cynicism $(0,78)$, Professional Efficacy $(0,68)$, Job Demands $(0,75)$, Lack of Resources $(0,78)$, Active Coping $(0,71)$, Passive Coping $(0,71)$, and Seeking Emotional Support $(0,75)$. Selected goodness-of-fit statistics related to the hypothesised model (Model 1) are presented in Table 6 .

TABLE 6

GOODNESS-OF-FIT STATISTICS FOR THE HYPOTHESISED MODEL

\begin{tabular}{lccccccccc}
\hline Model & $\chi^{2}$ & $\chi^{2} / \mathrm{df}$ & GFI & AGFI & PGFI & NFI & TLI & CFI & RMSEA \\
\hline Default model & 556,83 & 2,09 & 0,86 & 0,83 & 0,71 & 0,75 & 0,83 & 0,85 & 0,07
\end{tabular}

Table 6 shows that the overall statistically significant $\chi^{2}$ value (df $=266 ; p=0,00)$ is 556,83 . Given the known sensitivity of this statistic to sample size (Jöreskog \& Sörborn, 1993), use of the $\chi^{2}$ index provides little guidance in determining the extent to which the model does not fit. Therefore, it is more beneficial to rely on the other indexes of fit (Byrne, 2001). However, the hypothesised model (Model 1) was also not that good from this practical perspective. The PGFI value lower than 0,80, NFI, TLI and CFI values lower than 0,95 and RMSEA value higher than 0,05 are indicative of failure to confirm the hypothesised model. Thus it is apparent that some modification in specification is needed in order to determine a model that better represents the sample data.

Post hoc analyses

A review of the modification indices (MIs) reveals some evidence of misfit in the model. Parameters that represent the structural paths in the model as well as covariances between factors are the only MIs of interest. Based on the regression weights and the meaningfulness and influential flow, Model 1 was reestimated with one additional path from Seeking Emotional Support to Exhaustion. Covariances were allowed between Active Coping and Seeking Emotional Support and Job Demands and Lack of Resources. The $\chi^{2}$ value $(\mathrm{df}=266 ; \mathrm{p}=0,00)$ of this respecified model (model 2) is 365,23 . The $\chi^{2}$ difference between Models 1 and 2 was statistically significant $\left(\Delta \chi^{2}{ }_{(1)}=191,60\right)$. Furthermore, no MIs associated with structural paths were present in the output, only MIs related to covariances were present, but no values suggestive of model misfit. Taking these factors into account, no further consideration was given to the inclusion of additional parameters.

\section{Model parsimony}

Also important regarding model fit is the extent to which certain initially hypothesised paths may be irrelevant to the model (Byrne, 2001). In reviewing the structural parameter estimates for Model 2, two parameters were non-significant. These parameters represent the paths from Seeking Emotional Support to Cynicism (C.R. $=-0,71$ ) and Lack of Resources to Cynicism (C.R. $=-0,42)$. In the interest of parsimony, a final model of burnout was estimated with these two structural paths deleted from the model. The results of the final model (Model 3) are presented in Table 7 .

TABLE 7

GOODNESS-OF-FIT STATISTICS FOR MODEL 3

\begin{tabular}{lccccccccc}
\hline Model & $\chi^{2}$ & $\chi^{2} / \mathrm{df}$ & GFI & AGFI & PGFI & NFI & TLI & CFI & RMSEA \\
\hline Default model & 367,28 & 265 & 0,90 & 0,88 & 0,73 & 0,84 & 0,94 & 0,95 & 0,04 \\
\hline
\end{tabular}


Estimation of the final model (Model 3) resulted in an overall $\chi^{2}$ value $(\mathrm{df}=265 ; p=0,00)$ of 367,28 . As can be seen in Table 9 , there is a slight erosion in model fit from $\chi^{2}(262)=365,23$ for Model 2, to $\chi^{2}{ }_{(265)}=367,28$ for Model 3. However, with deletion of any parameters from a model, such a change is to be expected (Byrne, 2001). The important aspect of this change in model fit is that the ( 2 difference between the two models is not significant $\Delta \chi^{2}{ }_{(3)}=2,05$ ). Regarding the goodness-of-fit indexes the GFI value of 0,90 is indicative of good model fit. Although the PGFI value is not above 0,80, Mulaik et al. (1989) suggested that indices in the 0,90 's accompanied by PGFI's in the 0,50 's are not unexpected. The remaining indexes (TLI, CFI and RMSEA) are indicative of good fit, although the NFI value is rather low. A schematic representation of the final burnout model for police officers in the SAPS in Kwazulu-Natal is displayed in Figure 1.

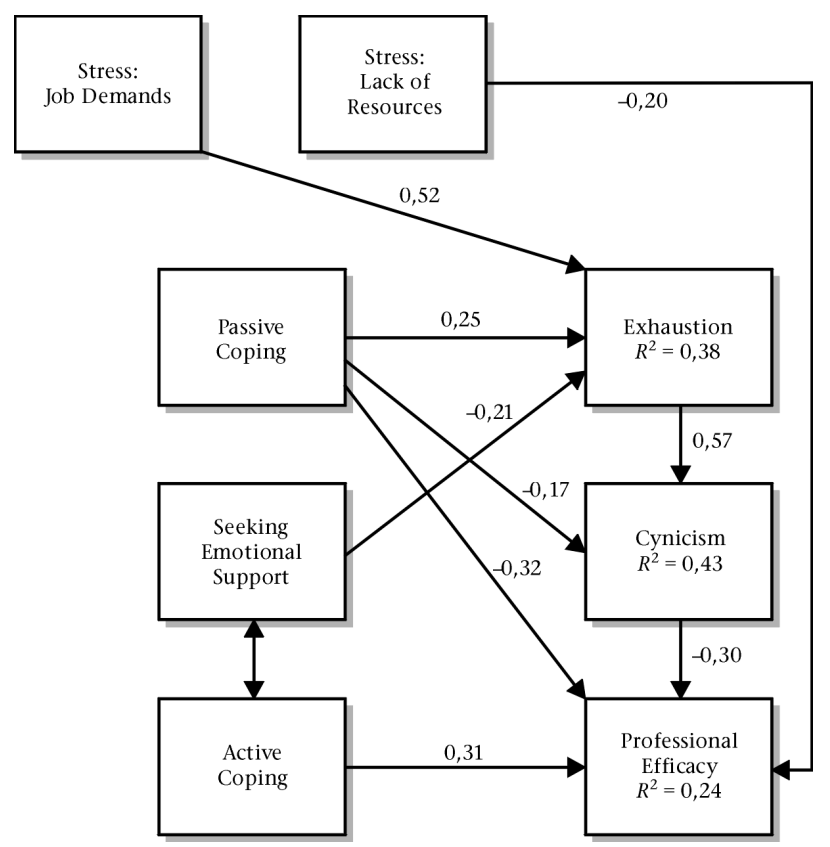

Figure 1: Model of burnout

According to the SMC's, 38\% of the variance associated with Exhaustion is accounted for by its predictors: Job Demands, Avoidance and Emotional Support. Regarding Cynicism, 43\% of the variance associated with this factor, is accounted for by Avoidance and Exhaustion. Lastly, 24\% of the variance associated with Professional Efficacy is accounted for by Active Coping, Avoidance and Lack of Resources.

\section{DISCUSSION}

The results show that stress associated with a lack of resources is relatively more severe than other stressors in the SAPS in Kwazulu-Natal. In this regard, inadequate salary, staff shortages and other officers not doing their job caused stress. Stressful job demands included having to deal with crisis situations, excessive paperwork, having to perform tasks not in the job description and having to do someone else's work. Also, seeing criminals go free was a relatively sever stressor for police members.

It is clear from the results of this study that stress because of job demands and a lack of resources were strongly related. This implies that stress because of a lack of resources probably increase the stress because of job demands. Not having resources (e.g. staff, money and equipment) probably makes it more difficult to deal with crisis situations, paperwork and performing tasks not in the job description.
A positive correlation between burnout and stress was found, as was expected from previous research by Burke (1994). High levels of stress because of job demands and a lack of job resources were related to high levels of exhaustion. It seems that stress because of job demands and a lack of job resources require greater effort from the police officer, resulting in more exhaustion. Job demands were also correlated with cynicism. High levels of stress are also related to poor coping strategies, as found in previous research (see Anshel, 2000; Violanti, 1992;). High job demands and a lack of job resources are associated with passive coping. It could therefore be said that not addressing a problem in full, (such as like when passive coping strategies are utilised), leads to stress in the individual.

With reference to coping and burnout, passive coping was related to exhaustion and cynicism. Canonical correlations showed high levels of passive coping to beare associated with high levels of exhaustion and cynicism and low levels of professional efficacy. These results confirm findings from previous research (see Rowe, 1997), where high levels of burnout were associated with ineffective or withdrawal coping strategies. One possibility for this could be that the stress that occurs from addressing the problem only in part, when passive coping strategies are adopted, accumulates until burnout occurs.

The structural equation analysis showed that occupational stress is associated with exhaustion. Although stress because of a lack of resources did not contribute directly to exhaustion, it was clear that job demands mediated the relationship between stress because of a lack of resources and exhaustion. Thus, officers experiencing high job demands (i.e. meeting deadlines, making critical on-the-spot decisions and dealing with crisis situations) experience higher exhaustion. Furthermore, when police officers used passive coping strategies, they showed an increase in exhaustion, but when they utilised their emotional support their level of exhaustion decreased. However, using an active coping strategy (such as concentrate their efforts on doing something about the problem) did not save them from feelings of exhaustion.

Passive coping was related to cynicism. Two interpretations of this finding are possible. Firstly, a passive coping strategy might have a direct effect on cynicism. Also, the structural equation modelling showed that exhaustion moderates the effect of passive coping on cynicism. Secondly, it is possible that cynicism (a form of mental disengagement from work), contributes to a passive coping strategy.

No relationship was found between cynicism and occupational stress. A possible explanation could be that stress because of job demands and a lack of resources influenced cynicism through exhaustion. In the SEM model, it is clear that feelings of exhaustion lead to cynicism. This is also consistent with the model of developmental sequence of the three dimensions as has been proposed by Leiter and Maslach (1988). Furthermore, no path was allowed between cynicism and professional efficacy in the SEM model. This is also consistent with the finding of Leiter (1993) that professional efficacy develops largely independently of exhaustion and cynicism. Therefore, it could be argued that stress because of job demands and a lack of resources lead to higher feelings of exhaustion, which, in turn, leads to higher levels of cynicism.

The use of passive coping strategies lead to lower feelings of accomplishment, while active coping strategies lead to higher feelings of professional efficacy in police officers' work. A lack of resources (i.e. insufficient personnel to help them handle an assignment, inadequate or poor quality equipment and lack of recognition for good work) leads to lower feelings of professional efficacy. 
A limitation of the research is that the research design does not allow one to determine the direction of the relationship between the variables (see Kerlinger \& Lee, 2000).

\section{RECOMMENDATIONS}

Tertiary interventions (e.g. counselling) should be used to decrease occupational stress and burnout in the SAPS in Kwazulu-Natal. Furthermore, secondary interventions (e.g. increasing awareness of stress, burnout and coping strategies) should be introduced in order to enhance the capacity of police members to cope with stress in the workplace.

When considering stressful job demands as a cause of burnout, aspects of the tasks of police officers, such as working overtime, frequent interruptions, excessive paper work and insufficient personal time should be targets for intervention. Furthermore, police management should attend to stress caused by a lack of resources (e.g. inadequate salary, staff shortages and other officers not doing their job). By reducing the stress caused by these factors, exhaustion and cynicism will decrease.

More research about stress and burnout in the SAPS is needed. Longitudinal studies could prove valuable in explicating the development of stress and burnout within the SAPS.

\section{REFERENCES}

Alexander, C. (1999). Police psychological burnout and trauma. In J.M. Violanti \& D. Paton (Eds.), Police trauma: Psychological aftermath of civilian combat (pp. 54-64). Springfield, IL: Charles C. Thomas.

Alsoofi, M.A., Al-Heeti, K.N. \& Alwashli, A. (2000). Burnout and its relationship with job stress and coping with stress for Yemeni teachers. Paper presented at the 28th International Congress of Psychology, Stockholm, Sweden.

Anderson, D.G. (2000). Coping strategies and burnout among veteran child protection workers. Child Abuse and Neglect, 24, 839-848.

Anon. (1986). Police and alcohol - Drink: An occupational hazard. Police Review, 92 (4742), 16-18.

Anshel, M.H. (2000). A conceptual model and implications for coping with stressful events in police work. Criminal Justice and Behavior, 27, 375-400.

Arbuckle J.L. (1997). Amos users' guide version 4.0. Chicago, IL: Smallwaters Corporation.

Bartol, C. R., Bergen, G. T., Volckens, J. S., \& Knoras, K. M. (1992). Women in small-town policing: Job performance and stress. Criminal Justice and Behavior, 19, 240-259.

Beehr, T.A., Johnson, L.B. \& Nieva, R. (1995). Occupational stress: Coping of police and their spouses. Journal of Organizational Behavior, 16, 3-25.

Biggam, F.H., Power, K.G., MacDonald, R.R., Carcary, W.B. \& Moodie, E. (1997). Self-perceived occupational stress distress in a Scottish police force. Work and Stress, 11, 118-133.

Billings, A.G. \& Moos, R.H. (1984). Coping, stress, and social resources among adults with unipolar depression. Journal of Personality and Social Psychology, 46, 877-891.

Brill, P.L. (1984). The need for an operational definition of burnout. Family \& Community Health, 6, 12-24.

Brown, J.M. \& Campbell, E.A. (1990). Sources of occupational stress in the police. Work and Stress, 4, 305-318.

Brown, J.M. \& Campbell, E.A. (1994). Stress and policing: Sources and strategies. Chichester: Wiley.

Brown, J., Cooper, C., \& Kirkcaldy, B. (1996). Occupational stress among senior police officers. British Journal of Psychology, 87, $31-41$.

Brown, J., \& Fielding, J. (1993). Qualitative differences in men and women police officers' experiences of occupational stress. Work \& Stress, 7 (2), 327-340.
Burke, R.J. (1993). Work-family stress, conflict, coping, and burnout in police officers. Stress Medicine, 9, 171-180.

Burke, R.J. (1994). Stressful events, work-family conflict, coping, psychological burnout, and well-being among police officers. Psychological Reports, 75, 787-800.

Burke, R.J. \& Richardsen, A.M. (1993). Psychological burnout in organizations. In R.T. Golembiewski (Ed.), Handbook of organizational behavior (pp. 263-298). New York: Dekker.

Byrne, B.M. (2001). Structural equation modeling with AMOS: Basic concepts, applications and programming. Mahwah, NJ: Erlbaum.

Carlier, I.V.E. \& Gersons, B.P.R. (1992). Development of a scale for traumatic incidents in police work. Psychiatria Fennica (Supplement) 23, 59-70.

Carver, C.S., Scheier, M.F. \& Wieintraub, J.K. (1989). Assessing coping strategies: A theoretical based approach. Journal of Personality and Social Psychology, 56, 267-283.

Chan, D.W. \& Hui, E.K.P. (1995, March). Burnout and coping among Chinese secondary school teachers in Hong Kong. British Journal of Educational Psychology, 65, 15-25.

Cherniss, C. (1980). Staff burnout. Beverly Hills, CA: Sage.

Chwalisz, K., Altmaier, E.M. \& Russell, D.W. (1992). Causal attributions, self-efficacy, cognitions and coping with stress. Journal of Social and Clinical Psychology, 11, 377-400.

Cherniss, C. (1980). Staff Burnout. Beverly Hills, CA: Sage.

Clark, L.A. \& Watson, D. (1995). Constructing validity: Basic issues in objective scale development. Psychological Assessment, 7, 309-319.

Cohen, J. (1988). Statistical power analysis for the behavioral sciences (Rev. ed.). Orlando, FL: Academic Press.

Constanza, R.S., Derlega, V.J. \& Winstead, B.A. (1988). Positive and negative forms of social support: Effects of conversational topics on coping with stress among same-sex friends. Journal of Experimental Social Psychology, 24, 182-193.

Cordes, C.L. \& Dougherty, T.W. (1993). A review and integration of research on job burnout. Academy of Management Review, $18,621-656$.

Crank, J. P. \& Caldero, M. (1991). The production of occupational stress in medium-sized police agencies: A survey of line officers in eight municipal departments. Journal of Criminal Justice, 19, 339-349.

Folkman, S., Lazarus, R.S., Gruen, R.J. \& DeLongis, A. (1986). Appraisal, coping, health status, and psychological symptoms. Journal of Personality and Social Psychology, 50, 571-579.

Golembiewski, R.T. \& Munzenrider, R.F. (1988). Phases of burnout: Developments in concepts and applications. New York: Preager.

Goodman, A.M. (1990). A model for police officer burnout. Journal of Business and Psychology, 5 (1), 85-99.

Gulle, G., Tredoux, C. \& Foster, D. (1998). Inherent and organisational stress in the SAPS: An empirical survey in the Western Cape. South African Journal of Psychology, 28, 129134.

Hobfoll, S.E. (1989). Conservation of resources: A new attempt at conceptualizing stress. American Psychologist, 44, 513-524.

Hobfoll, S.E. \& Freedy, J. (1993). Conservation of resources: A general stress theory applied to burnout. In W.B. Schaufeli, C. Maslach, \& T. Marek (Eds.), Professional burnout: Recent developments in theory and research (pp. 115-129). Washington, DC: Taylor \& Francis.

Hobfoll, S.E., Freedy, J., Lane, C. \& Geller, P. (1990, November). Conservation of social resource theory. Journal of Social and Personal Relationships, 7, 465-478.

Hoyle, R.H. (1995). The structural equation modeling approach: Basic concepts and fundamental issues. In R.H. Hoyle (Ed.), Structural equation modeling: Concepts, issues, and applications (pp. 1-15). Thousand Oaks, CA: Sage.

Hu, L.-T. \& Bentler, P.M (1999). Cutoff criteria for fit indexes in covariance structure analysis: Conventional criteria versus new alternatives. Structural equation modeling: A Multidisciplinary Journal, 6, 1-55. 
Jöreskog, K.G. \& Sörbom, D. (1993). LISREL 8: Structural equation modeling with the SIMPLIS command language. Hillsdale, NJ: Lawrence Erlbaum Associates.

Kerlinger, F.N. \& Lee, H.B. (2000). Foundations of behavioral research ( $4^{\text {th }}$ ed.) Orlando, FL: Harcourt.

Kirkcaldy, B., Cooper, C.L. \& Ruffalo, P. (1995, April). Work stress and health in a sample of U.S. police. Psychological Reports, 76, 700-706.

Kirkcaldy, B., Cooper, C.L., \& Ruffalo, P. (1995). Work stress and health in a sample of U.S. police. Psychological Reports, 76, 700-702.

Koortzen, P. (1996). Die dimensionaliteit van polisie-stressore. Acta Criminologica, 9 (2), 55-63.

Kop, N., Euwema, M. \& Schaufeli, W. (1999). Burnout, job stress and violent behavior among Dutch police. Work and Stress, $13,326-340$.

Kop, N. \& Euwema, M. C. (2001). Occupational stress and the use of force by Dutch police officers. Criminal Justice and Behavior, 28 (5), 631-652.

Kop, N., Euwema, M., \& Schaufeli, W. (1999). Burnout, job stress and violent behavior among Dutch police. Work and Stress, $13,326-340$.

Lazarus, R.S. \& Folkman, S. (1984). Stress, appraisal and coping. New York: Springer.

Lee, R.T. \& Ashforth, B.E. (1996). A meta-analytical examination of the correlates of the three dimensions of job burnout. Journal of Applied Psychology, 81, 123-133.

Leiter, M.P. (1991). Coping patterns as predictors of burnout: The function of control and escapist coping patterns. Journal of Organizational Behavior, 12, 123-144.

Leiter, M.P. (1993). Burnout as a developmental process: Consideration of models. In W.B. Schaufeli, C. Maslach \& T. Marek (Eds.), Professional burnout: Recent developments in theory and research (pp. 237-250). Washington, DC: Taylor \& Francis.

Leiter, M.P. \& Maslach, C. (1988). The impact of interpersonal environment on burnout and organizational commitment. Journal of Organizational Behavior, 9, 297-308.

Maslach, C. (1982). Burnout: The cost of caring. Englewood Cliffs, NJ: Prentice Hall.

Loo, R. (1984). Occupational stress in the law enforcement profession. Canada's Mental Health, 32 (3), 10-13.

Maslach, C. (1982). Understanding burnout: Definitional issues in analyzing a complex phenomenon. In W.S. Paine (Ed.), Job stress and burnout: Research, theory, and intervention (pp.2940). Beverly Hills, CA: Sage.

Maslach, C. \& Jackson, S.E. (1982). Burnout in health professions: A social psychological analysis. In G. Sanders \& J. Suls (Eds.), Social psychology of health and illness. Hillsdale, NJ: Erlbaum.

Maslach, C., Schaufeli, W.B. \& Leiter, M.P. (2001). Job burnout. Annual Review of Psychology, 52, 397-422.

McCafferty, F.L., McCafferty, E. \& McCafferty, M.A. (1992). Stress and suicide in police officers: Paradigm of occupational stress. Southern Medical Journal, 85, 233-243.

Mitchell, G. \& Hastings, R.P. (2001, September). Coping, burnout, and emotion in staff working in community services for people with challenging behaviors. American Journal on Mental Retardation, 106, 448-459.

Mulaik, S.A., James, L.R., Van Altine, J., Bennett, N., Lind, S. \& Stillwell, C.D. (1989). Evaluation of goodness-of-fit indices for structural equation models. Psychological Bulletin, 105, 430-445.

Nel, J. \& Burgers, T. (1998). Stress and trauma in the work environment: The South African Police Service. Unisa Psychologia, 25 (2), 17-25.

$\mathrm{Nel}, \mathrm{J}$. (1999). Police officials as victims of trauma and crises. Unisa Psychologia, 26 (1\&2), 32-42.

Nunnally, J.C. \& Bernstein, I.H. (1994). Psychometric theory (3 ${ }^{\text {rd }}$ ed.). New York: McGraw-Hill.

Paton, D. \& Violanti, J.M. (1999). Trauma stress in policing: Issues for future consideration. In J.M. Violanti \& D. Paton
(Eds.), Police trauma: Psychological aftermath of civilian combat (pp. 293-297). Springfield, IL: Charles, C. Thomas.

Patterson, G.T. (1999). Coping effectiveness and occupational stress in police officers. In J.M. Violanti and D. Paton, Police trauma: Psychological aftermath of civilian combat (pp. 214226). Springfield, IL: Charles, C. Thomas.

Peeters, M.C.W. \& Le Blanc, P.M. (2001). Towards a match between job demands and sources of social support: A study among oncology care providers. European Journal of Work and Organizational Psychology, 10, 53-72.

Patterson, B. L. (1992). Job experience and perceived job stress among police, correctional, and probation/parole officers. Criminal Justice and Behavior, 19, 260-285.

Pienaar, J. \& Rothmann, S. (in 2002press). Coping, stress and suicide ideation in the South African Police Services. Unpublished doctoral thesis, PU for CHE, Pothefstroom.

Pieters, H.G. (1995). Psigiese uitbranding by onder-offisiere in die Suid-Afrikaanse Polisiediens. Ongepubliseerde meestersgraadskripsie, PU vir CHO, Potchefstroom.

Pines, A., Aronson, E. \& Kafry, D. (1981). Burnout: From tedium to personal growth. New York: Free Press.

Rohman, C. (1987/1988). A study of burnout among psychologists. Dissertation Abstracts International, 48, 2772.

Rothmann, S. \& Van Rensburg, P. (2002). Psychological strengths, coping and suicide ideation in the South African Police Services in the North West Province. South African Journal of Industrial Psychology, 28 (3), 39-49.

Rowe, M. (1997). Hardiness, stress, temperament, coping, and burnout in health professionals. American Journal of Health Behaviour, 21 (3), 163-171.

SAS Institute. (2000). The SAS system for Windows: Release 8.01. Cary, NC: SAS Institute Inc.

Schaufeli, W.B. \& Enzmann, D. (1998). The burnout companion to study and practice: A critical analysis. Philadelphia: Taylor \& Francis Ltd.

Schaufeli, W.B., Leiter, M.P., Maslach, C. \& Jackson, S.E. (1996). MBI-General Survey. In C. Maslach, S.E. Jackson \& M.P. Leiter (Eds.), Maslach Burnout Inventory Manual (3 $3^{\text {rd }}$ ed.). Palo Alto, CA: Consulting Psychologists Press.

Schaufeli, W.B., Leiter, M.P., Maslach, C. \& Jackson, S.E. (1996). MBI-General Survey. In C. Maslach, S.E. Jackson, \& M.P. Leiter (Eds.), Maslach Burnout Inventory Manual (3 ${ }^{\text {rd }}$ ed.). Palo Alto, CA: Consulting Psychologists Press.

Shaughnessy, J.J. \& Zechmeister, E.B. (1997). Research methods in psychology (4th ed.). New York: McGraw-Hill.

Storm, K. \& Rothmann (2002). Burnout and work engagement in the South African Police Services. Unpublished doctoral thesis, PU for CHE, Potchefstroom.

Storm, K. \& Rothmann, S. (2003). The relationship between personality dimensions, coping and burnout of pharmacists in a corporate pharmacy group. South African Journal of Industrial Psychology, 29 (4).

Tabachnick, B.G. \& Fidell, L.S. (2001). Using multivariate statistics ( $4^{\text {th }}$ ed.). Boston, MA: Allyn \& Bacon.

Taris, T.W., Schreurs, P.J.G. \& Schaufeli, W.B. (1999). Construct validity of the Maslach Burnout Inventory - General Survey: A two-sample examination of its factor structure and correlates. Work and Stress, 13, 223-237.

Teague, J.B. (1992). The relationship between various coping styles and burnout among nurses. Unpublished doctoral dissertation, Ball State University.

The reported serious crime situation in South Africa for the period January - September 2001 (2001, December). Retrieved February 4, 2002, from the World Wide Web: http://www.saps.org.za/8_crimeinfo/200112/report.htm.

Tucker, L.R. \& Lewis, C. (1973). A reliability coefficient for maximum likelihood factor analysis. Psychometrika, 38, 1-10.

Strümpfer, D.J.W. (1995). The origins of health and strength: From salutogenesis to fortigenesis. South African Journal of Psychology, 25, 81-89.

Terry, W. C. III. (1981). Police stress: The empirical evidence. Journal of Police Science and Administration, 9 (1), 61-75. 
Van Dierendonck, D., Schaufeli, W.B. \& Buunk, A.P. (1998). The evaluation of an individual burnout intervention program: The role of inequity and social support. Journal of Applied Psychology, 83, 392-407.

Venter, E. (1993). Uitbrandingsindroom: 'n Definisie, die simptome en die fases. Servamus, 86 (10), 22-26.

Violanti, J.M. (1992). Coping strategies among police recruits in a high-stress training environment. Journal of Social Psychology, 132, 717-729.

Violanti, J. M. \& Aron, F. (1994). Ranking police stressors. Psychological Reports, 75, 824-826.

Violanti, J.M., Marshall, J.R. \& Howe, B. (1985). Stress, coping, and alcohol use: The police connection. Journal of Police Science and Administration, 13, 106-110.
Wheaton, B., Muthén, B., Alwin, D.F. \& Summers, G.F. (1977) Assessing reliability and stability in panel models. In D.R. Heise (Ed), Sociological methodology (pp. 84-136). San Francisco, CA: Jossey-Bass.

Zellars, K.L. \& Perrewe, P.L. (2001, June). Affective personality and the content of emotional social support: Coping in organizations. Journal of Applied Psychology, 86, 459-467.

Wexler, J. G. \& Logan, D. D. (1983). Sources of stress among women police officers. Journal of Police Science and Administration, 11 (1), 46-53.

White, J. W., Lawrence, P. S., Biggerstaff, C., \& Grubb, T. D. (1985). Factors of stress among police officers. Criminal Justice and Behavior, 12 (1), 111-128. 